Research Article

\title{
Research on the Ecological Protection of Coal Gangue Slope Based on a Polymer Curing Agent
}

\author{
Jian Zhang $(\mathbb{D}$, Wen Yi $(\mathbb{D}$, Weijia Yuan, Yifang Liu, and Zifan Sui \\ School of Civil Engineering, Central South University of Forestry and Technology, Changsha 410004, China \\ Correspondence should be addressed to Wen Yi; yiwengangbiao@163.com
}

Received 19 August 2021; Accepted 6 November 2021; Published 18 November 2021

Academic Editor: Baskaran Rangasamy

Copyright (C) 2021 Jian Zhang et al. This is an open access article distributed under the Creative Commons Attribution License, which permits unrestricted use, distribution, and reproduction in any medium, provided the original work is properly cited.

\begin{abstract}
To improve the ecological protection of coal gangue slopes, this work developed a polymer curing agent using a pure acrylic emulsion and cement as the main raw materials. By testing the workability, waterproofing, durability, and adhesion of the curing agent with different polymer-to-cement ratios, the optimum mixing ratio of the polymer curing agent was obtained, and the protection mechanism was analysed based on the test results and by scanning electron microscopy (SEM). Then, simulated slope and practical engineering applications were carried out. The results show that pure acrylic emulsion curing agent with a polymerto-cement ratio of 6:5 is most suitable for the ecological protection of coal gangue slopes. The polymer curing agent can form a network structure film layer with a good waterproofing effect on the coal gangue surface. Simultaneously, the network structure film layer can reduce the influence of weathering and leaching on the coal gangue, prevent the heavy metal elements in coal gangue from entering the surrounding soil, improve the growth environment of plants, and improve the effect of ecological restoration. This research can be applied to the ecological protection of coal gangue slopes.
\end{abstract}

\section{Introduction}

Coal gangue is solid waste discharged in the process of coal mining and washing. It is a black, grey rock with a lower carbon content and harder structure than coal and is associated with the coal seam in the process of coal formation. Under weathering, the physical and chemical properties of coal gangue accumulating on the ground continuously change; with the increase in degree of weathering, the conductivity and $\mathrm{pH}$ of coal gangue decrease, and its tendency to disintegrate gradually increases [1]. Coal gangue piled in open air is prone to spontaneous combustion, generates harmful gases and heavy metals, and results in severe geological disasters and environmental pollution $[2,3]$. Under the action of weathering and leaching, heavy metal elements in coal gangue enter the surrounding soil and water, degrade the ecological environment, and hinder plant growth and ecological restoration [4-6]. Gangue slopes are special rock slopes formed by gangue accumulation that are more complex and difficult to protect. Gangue slopes are often unstable due to the weathering and disintegration of gangue. Due to the influence of the unfavourable properties of gangue, plants cannot grow normally on these slopes, and it is difficult to achieve the desired ideal slope protection effects using conventional ecological protection methods [7-10].

Currently, mortar plaster, concrete, wall protection, and other methods are commonly used to protect coal gangue slopes. Although these methods have good protection effects, materials such as mortar and concrete hinder the growth of plants, and it is difficult to achieve the goals of both slope protection and ecological restoration [11-14]. Ecological protection mainly relies on the reinforcing effect of plant roots on soil to achieve the slope protection effect. The commonly used methods include soil spraying, plant fibre blankets, and planting belts. The key to the effect of slope protection by these methods is the normal growth of plants on the slope [15-20]. Coal gangue after spontaneous combustion shows weak acid and high heavy metal contents that are not conducive to plant growth. Many researchers have studied the reclamation of coal mining areas. For example, Sydnor et al. [21] found that the addition of organic 
matter to surface soil could increase the biomass and required nutrient elements for plant growth in mining areas and promote the restoration of vegetation in mining areas. Liu et al. [22] improved the growth environment of plants in mining areas by covering coal gangue with loess and achieved good ecological restoration results. Du et al. [23] used coal gangue as the component of planting substrate, configured a planting substrate suitable for ecological restoration in coal mine areas, and proved that the new substrate configuration was effective through experiments. Although these studies have made some progress in the reclamation of coal mine areas, their application is limited due to different properties of coal gangue in different areas, and the existing vegetation restoration methods cannot solve the problem that coal gangue is prone to weathering and disintegration.

Polymer curing agents are chemical reinforcement materials mainly composed of polymer materials and supplemented by other materials. There are many polymer curing agents, and they have been widely used in the field of soil reinforcement and slope protection in recent years [24-30]. Liu et al. [31-33] developed a polyurethane polymer curing agent, conducted a thorough study on its properties of strengthening sand and clay, and found that the polyurethane polymer curing agent mainly increased the cohesion between the soil particles and the erosion resistance of slope soil through the physical and chemical action between the polymer functional groups and the surface ions of soil particles. Yang et al. [34] developed a new polymer soil stability additive (M-CMC) composed of methyl cellulose (CMC) and polyacrylamide (PAM) and experimentally showed that it could improve the soil strength, water stability, and erosion resistance. Yao et al. [35] developed a polymer curing agent suitable to protect soft rock slopes, and practical engineering applications showed that its protection effect was good and conducive to the ecological restoration of soft rock slopes. Qin et al. [36] adopted W-OH hydrophilic polyurethane material to solidify and protect red clay slopes, and based on experiments, they concluded that $\mathrm{W}-\mathrm{OH}$ could significantly improve the antierosion ability of red clay slope soil, increase the water retention performance of the soil, and promote the germination and growth of plants on the slope. Therefore, the study of the application of polymer curing agents in the ecological protection of gangue slopes is highly important.

To solve the problems posed by coal gangue, such as easy weathering, easy disintegration in water, low $\mathrm{pH}$ value, high heavy metal content, and difficulties in the ecological protection of slopes, this work uses a pure acrylic emulsion and ordinary Portland cement as the main raw materials and polymer curing agents with different polymer-to-cement ratios. The optimal mixing ratio of polymer curing agent suitable for coal gangue slope protection was determined through workability, waterproofing, durability, and adhesion tests. Simultaneously, the protection mechanism was analysed by matching the test results and scanning electron microscopy (SEM) images. Finally, a new method for the ecological protection of gangue slopes with polymer curing agents was proposed and applied to simulated slopes and in actual engineering practice. Then, the application effect of polymer curing agents in the ecological protection of gangue slopes was analysed according to the application results.

\section{Materials and Methods}

\subsection{Materials}

2.1.1. Polymer Emulsion. Polymer emulsions are formed by dispersing polymer particles in micron aqueous solutions that show good water resistance, durability, and bond strength and are important raw materials for the configuration of polymer curing agents. Considering the difficulty of obtaining raw materials and suitability for ecological slope protection, a pure acrylic emulsion produced by Luyuan Chemical Company was selected as the configuration of the polymer curing agent. As a widely used waterproof building material, pure acrylic emulsions are easy to obtain, environmentally friendly, and conducive to ecological restoration. Pure acrylic emulsion is shown in Figure 1. The performance index of the pure acrylic emulsion indicated by the manufacturing company is shown in Table 1.

2.1.2. Cement. Cement is also one of the main components of polymer curing agents, and its type and dosage directly affect the strength of polymer curing agents. In consideration of economy and durability, common silicate P.O42.5 cement produced by Yangchun Cement Limited Company was selected to configure the polymer curing agent. The performance indices of the P.O42.5 cement indicated by the manufacturing company are shown in Table 2.

2.1.3. Coalescing Agents. A coalescence agent is a material that can promote the plastic flow and elastic deformation of polymer emulsions, improve their coalescence performance, and form films over a wide range of construction temperatures. It can clearly reduce the minimum film forming temperature of polymer emulsions and improve their coalescence, durability, and storage stability. In this experiment, the alcohol ester coalescing agents produced by Luyuan Chemical Company were used in the polymer emulsion material configuration. The performance indices of the film forming additives indicated by the manufacturing company are shown in Table 3.

2.1.4. Defoaming Agent. When mixing a polymer emulsion and cement, many bubbles will be generated. Bubbles will cause many pores to solidify the curing agent, which affects the curing effect. Therefore, an appropriate amount of defoamer should be added in the preparation process to reduce the number of bubbles and enhance the curing effect of the polymer curing agent. In this work, an emulsion-type silicone defoamer produced by Luyuan Chemical Company was used to configure the polymer curing agent. The performance indices of the silicone defoamer agent indicated by the manufacturing company are shown in Table 4. 


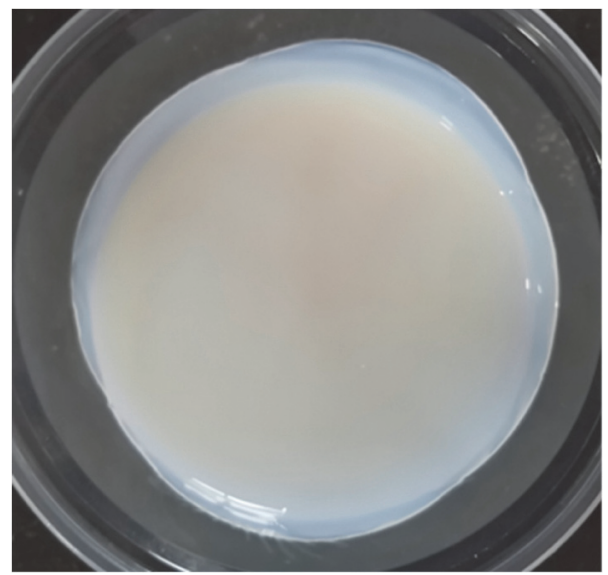

Figure 1: Pure acrylic emulsion.

TABle 1: Performance indices of pure acrylic emulsion.

\begin{tabular}{lcc}
\hline Order number & Technical indicators & Test results \\
\hline 1 & Appearance & Milky white uniform liquid, no impurities, no precipitation, and no stratification \\
2 & Solid content (\%) & 50 \\
3 & $\mathrm{pH}$ & 7.4 \\
4 & Viscosity (mPa.s) & 800 \\
5 & Residual stability $(\%)$ & 0.03 \\
\hline
\end{tabular}

TABle 2: Performance indices of P.O42.5 cement.

\begin{tabular}{lccc}
\hline Order number & Technical indicators & Test conditions & Test results \\
\hline 1 & Fineness & - & $14.0 \%$ \\
2 & Standard consistency & - & $25.2 \%$ \\
$105 \mathrm{~min}$ \\
3 & Curing time & Initial curing & $229 \mathrm{~min}$ \\
& & Final curing & $6.2 \mathrm{MPa}$ \\
4 & Rupture strength $(\mathrm{MPa})$ & $3 \mathrm{~d}$ & $8.3 \mathrm{MPa}$ \\
& & $28 \mathrm{~d}$ & $26.8 \mathrm{MPa}$ \\
5 & Compressive strength $(\mathrm{MPa})$ & $3 \mathrm{~d}$ & $59.1 \mathrm{MPa}$ \\
\hline
\end{tabular}

TABle 3: Performance indices of coalescing agents.

\begin{tabular}{lcc}
\hline Order number & Technical indicators & Test results \\
\hline 1 & Appearance & Colourless transparent liquid, without soluble matter \\
2 & Freezing point $\left({ }^{\circ} \mathrm{C}\right)$ & -50.0 \\
3 & Flash point $\left({ }^{\circ} \mathrm{C}\right)$ & 120 \\
\hline
\end{tabular}

Table 4: Performance indices of the silicone defoamer agent.

\begin{tabular}{lcc}
\hline Order number & Technical indicators & Test results \\
\hline 1 & Appearance & Milky white uniform emulsion liquid, no precipitate, no visible mechanical impurities \\
2 & $\mathrm{pH}$ & 7.2 \\
3 & Solid content (\%) & 15 \\
4 & Stability (mL) & 0.02 \\
5 & Defoaming time (s) & 11 (10 times) \\
\end{tabular}

2.2. Configuration Method. The pure acrylic emulsion curing agent consists of a pure acrylic emulsion with waterproof performance, cement, small amounts of coalescing agents, and defoaming agent. It is a polymer cement-based composite material with the main properties of pure acrylic emulsion and cement. The pure acrylic emulsion curing agent can be prepared by simple stirring and mixing. Under normal temperature and pressure, the raw materials were 
weighed according to the weight percentage of each raw material, and the pure acrylic emulsion was artificially stirred at low speed for $60 \mathrm{~s}$. Then, the corresponding amount of cement was added to the pure acrylic emulsion. Finally, the mixture was stirred by a cement mixer at high speed for $120 \mathrm{~s}$ and left standing for $300 \mathrm{~s}$. To reduce the bubbles generated during mixing, $1 \%$ of the total weight of the mixture defoaming agent was added during mechanical mixing. Simultaneously, $3 \%$ of the total weight of the mixture coalescing agents was added to ensure the final filmforming effect.

2.3. Test Methods. The weight ratio between the content of the polymer solid particles in the polymer curing agent and the mass of cement is called the polymer-to-cement ratio and expressed by $\mathrm{P} / \mathrm{C}$. In this work, five pure acrylic emulsion curing agents with different polymer-to-cement ratios $(\mathrm{P} / \mathrm{C}=0.6,0.8,1,1.2,1.4)$ were set up; then, mixing proportion tests were performed, including workability tests, waterproof property tests, durability tests, and adhesion tests. Based on the test results, the mixing ratio of the pure acrylic emulsion curing agent that was most suitable for coal gangue slope protection was obtained, and the protective mechanism was analysed by scanning microscopy.

2.3.1. Workability Test. The workability of the polymer curing agent refers to its setting time and viscosity, which represent the difficulty of its construction. If the initial setting time is too short, the construction is difficult; if the final setting time is too long, the construction progress will be affected. In this test, according to the test method of cement setting time in the China standard (GB/T 1346-2011) [37], a Vicat instrument was used to test the curing time of pure acrylic emulsion curing agents with different polymer-to-cement ratios. The viscosity of the polymer curing agent represents the friction force of its internal molecules. Greater viscosity corresponds to smaller fluidity and leads to greater difficulty of construction. Meanwhile, a smaller viscosity corresponds to greater fluidity, delamination, and segregation. According to the Chinese standard (JJG 1002-2005) [38], a rotary viscometer was used to determine the viscosity of the pure acrylic emulsion curing agent.

2.3.2. Waterproof Test. The waterproofing ability of the polymer curing agent is an important index to evaluate its performance and the basis to solve the problem of the easy disintegration of coal gangue when encountering water. The water resistance can be expressed by the natural water absorption rate of the material, that is, under the condition of standard atmospheric pressure, the ratio of the mass of water in the experimental specimen that was soaked in water for $48 \mathrm{~h}$ to the mass of the dried experimental specimen. In this work, coal gangue with basically identical size was selected as the test specimen, and polymer curing agents with different polymer-cement ratios were evenly applied to the sample with a coating thickness of 5-6 $\mathrm{mm}$ for the $48 \mathrm{~h}$ waterproof test. The experiment was performed according to the steps of the rock water absorption test in the Chinese standard (JTG E41-2005) [39]. The coal gangue sample coated with pure acrylic emulsion curing agent is shown in Figure 2.

2.3.3. Durability Test. The durability of the polymer curing agent represents its long-term protection performance and is an important parameter to evaluate whether the agent is suitable for coal gangue slope protection. In this work, the durability of the curing agent of a pure acrylic emulsion was evaluated by the number of cracks produced by gangue samples with different polymer-to-cement ratios. The test is based on the frost resistance test method specified in the China Standard (JC/T 984-2011) [40], and the number of cracks on the surface of the specimens after 25 cycles of drying and wetting was observed.

2.3.4. Adhesion Test. The bonding strength of the polymer curing agent usually refers to the cohesion of the polymer curing agent and the bonding force between the specimen coating and the bonding surface, which indicates the strength of its bonding. A greater bonding strength makes it more difficult for the agent to fall off on the slope surface and leads to an improved protection effect. In this work, referring to the test method of mortar tensile bond strength in the Chinese code (JGJ/T70-2009) [41], a tensile testing machine was used to test the bond strength of the pure acrylic emulsion curing agent.

2.3.5. Microscanning Test. In this paper, a HITACHI SU8100 scanning electron microscope (SEM, Hitachi, Japan) was used to conduct the scanning microscopy test. Under the condition of 1000-fold magnification, the microscopic surface morphology characteristics of coal gangue specimens sprayed with different polymer-to-cement ratios of pure acrylic emulsion curing agent and coal gangue specimens not sprayed with curing agent were observed.

\section{Results and Discussion}

3.1. Mixing Ratio Test. The test results for the workability, waterproofing ability, durability, and adhesion of the curing agent of pure acrylic emulsions with different polymer-tocement ratios are shown in Table 5 .

Table 5 shows that a greater $\mathrm{P} / \mathrm{C}$ leads to a longer setting time of the pure acrylic emulsion curing agent, smaller viscosity, and greater fluidity. With the increase in $\mathrm{P} / \mathrm{C}$, the water absorption rate of the test specimen gradually decreases and tends to be stable. The number of cracks on the surface of the test specimen and bonding strength of the curing agent first decrease and subsequently increase. When $\mathrm{P} / \mathrm{C}$ is 1.2 , the number of cracks on the surface of the test specimen is lowest, and the curing agent has the maximal bonding strength. The workability of the pure acrylic emulsion curing agent mainly depends on the cement content, so with the increase in $\mathrm{P} / \mathrm{C}$, the cement content shows a relative decrease, the setting time of the curing agent 


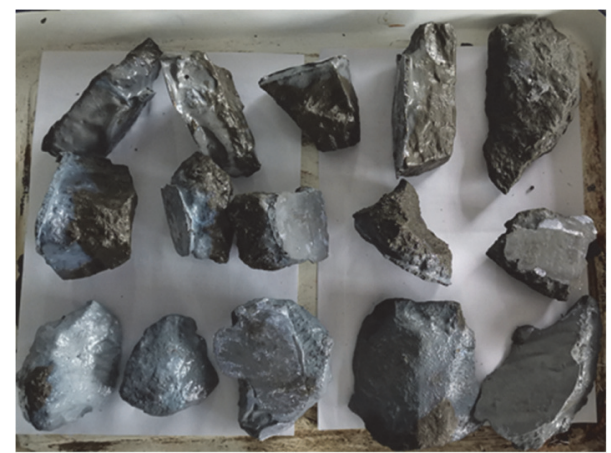

FIgURE 2: Coal gangue specimens coated with pure acrylic emulsion curing agent.

TABle 5: Performance test results for pure acrylic emulsion curing agents with different polymer-to-cement ratios.

\begin{tabular}{lcccccc}
\hline $\begin{array}{l}\text { P/ } \\
\text { C }\end{array}$ & $\begin{array}{c}\text { Initial setting time } \\
(\mathrm{min})\end{array}$ & $\begin{array}{c}\text { Final setting time } \\
(\mathrm{min})\end{array}$ & Viscosity (MPa)s $)$ & $\begin{array}{c}\text { Bibulous rate } \\
(\%)\end{array}$ & $\begin{array}{c}\text { Number of } \\
\text { cracks }\end{array}$ & Bonding strength (MPa) \\
\hline 0.6 & 104 & 341 & 64 & 5.71 & 6 & 1.54 \\
0.8 & 113 & 382 & 56 & 3.15 & 4 & 1.73 \\
1.0 & 126 & 429 & 48 & 1.42 & 2 & 1.96 \\
1.2 & 134 & 447 & 46 & 0.39 & 1 & 2.05 \\
1.4 & 151 & 524 & 44 & 0.33 & 3 & 1.86 \\
\hline
\end{tabular}

becomes longer, and the viscosity decreases. The workability of pure acrylic emulsion curing agents with different polymer-to-cement ratios can satisfy the construction requirements, and the workability is the best when $\mathrm{P} / \mathrm{C}$ is 1.2.

When $\mathrm{P} / \mathrm{C}$ is small, the cement content in the curing agent is relatively high, and the polymer emulsion content is low. The hydration product of cement is mainly the network structure, and a small amount of polymer particles cannot completely fill the network structure. Therefore, the polymer network structure film formed is relatively small, which results in a relatively large water absorption of gangue sample block. With the increase in $\mathrm{P} / \mathrm{C}$, the polymer emulsion plays a dominant role in the curing agent, and the formed network film almost completely covers the surface of gangue, which decreases the water penetration rate and water absorption rate of the test block. The lowest value is obtained when $\mathrm{P} / \mathrm{C}$ is 1.2 . The bonding strength of the polymer curing agent is mainly determined by the solid content of the polymer emulsion and hydration product of cement. When $\mathrm{P} / \mathrm{C}$ is less than 1.2, the content of pure acrylic emulsion increases with increasing $\mathrm{P} / \mathrm{C}$, and so, the bonding strength increases. When $\mathrm{P} / \mathrm{C}$ is greater than 1.2 , the bonding strength of the pure acrylic emulsion reaches its peak, the cement content in the polymer curing agent is relatively reduced, and the content of cement hydration products is relatively reduced, and so, the bonding strength begins to decrease. According to the mixing ratio test, the pure acrylic emulsion curing agent with a $\mathrm{P} / \mathrm{C}$ of 1.2 is most suitable for the protection of coal gangue slopes.

3.2. Microscopy Results. The scanning electron microscopy (SEM) results of coal gangue specimens are shown in Figure 3.
As shown in Figure 3(a), the surface of coal gangue is loose and porous. Under infiltration and erosion by rain, it is easily weathered and disintegrated. As shown in Figures 3(b)-3(f) the polymer particles of the pure propylene emulsion and hydration products of cement connect with each other, which form a reticular membrane structure. When $\mathrm{P} / \mathrm{C}$ is less than 1.2 , the content of pure acrylic emulsion is small, polymer particles are not sufficient to completely wrap the cement hydration product, and the network film formed has more pores, which makes the curing agent waterproof and endows it with poor durability. With the increase in $\mathrm{P} / \mathrm{C}$, the pores of the curing agent of the pure acrylic emulsion gradually decrease. When $\mathrm{P} / \mathrm{C}$ is 1.2 , the polymer particles almost completely wrap around the hydration product of cement, which leads to a lower porosity of the curing agent film and good waterproofing performance. When $\mathrm{P} / \mathrm{C}$ is greater than 1.2, the content of cement hydration products in the curing agent film decreases, and the strength of the curing agent film also decreases. Therefore, the durability and bond strength gradually decrease.

In summary, after pure acrylic emulsion has been mixed with cement, the pure acrylic emulsion loses water due to cement hydration, and its polymer particles and cement hydration products interweave and intertwine to form a mesh film with good waterproof ability. By spraying pure acrylic emulsion curing agent on the surface of coal gangue, we can bond and solidify the loose and porous surface of coal gangue. The network film that covers the surface of coal gangue can increase its waterproof ability, prevent its weathering and disintegration, and improve the long-term stability of coal gangue slopes. 


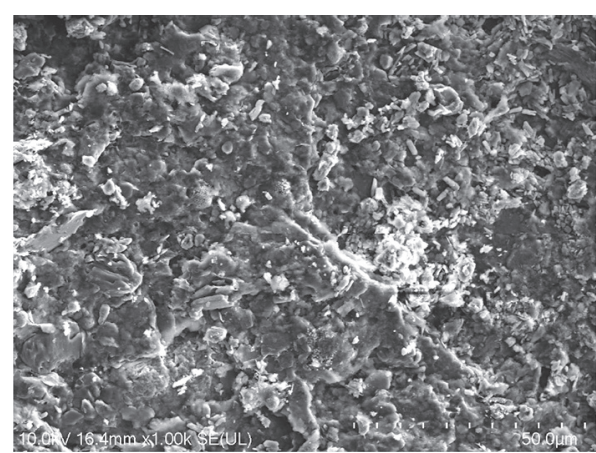

(a)

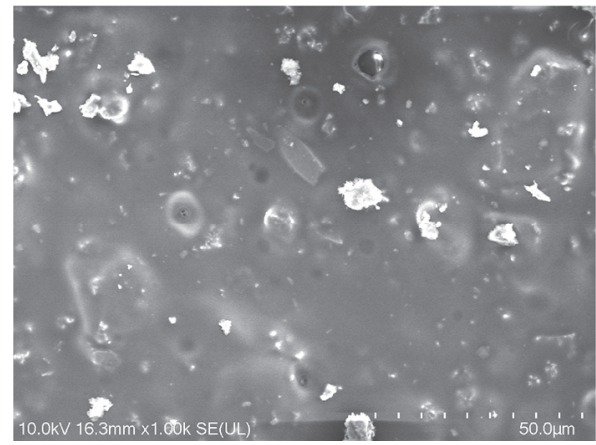

(c)

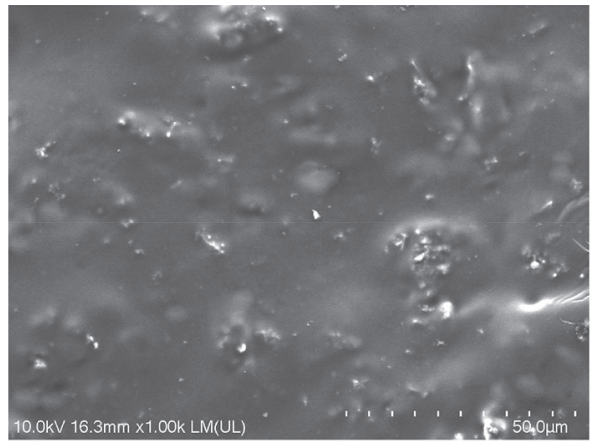

(e)

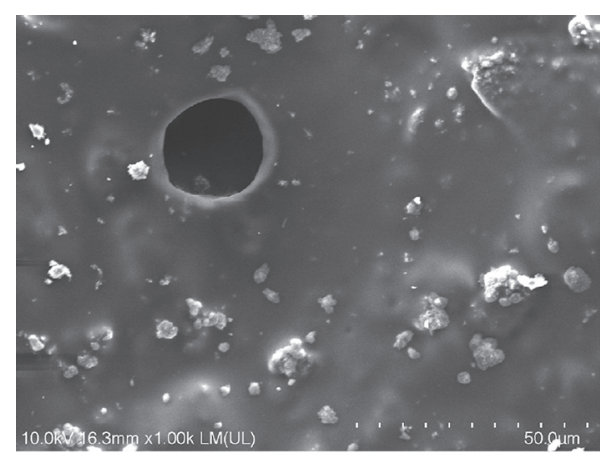

(b)

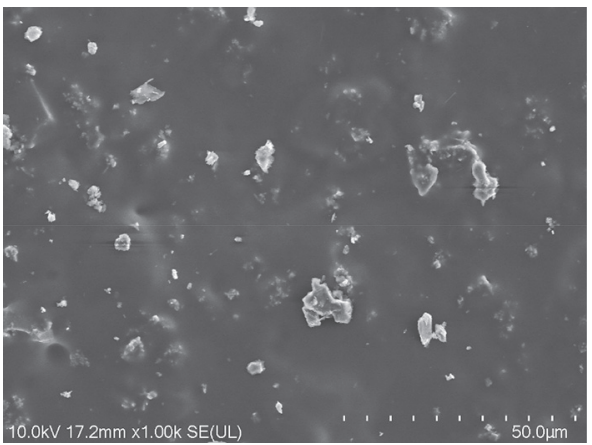

(d)

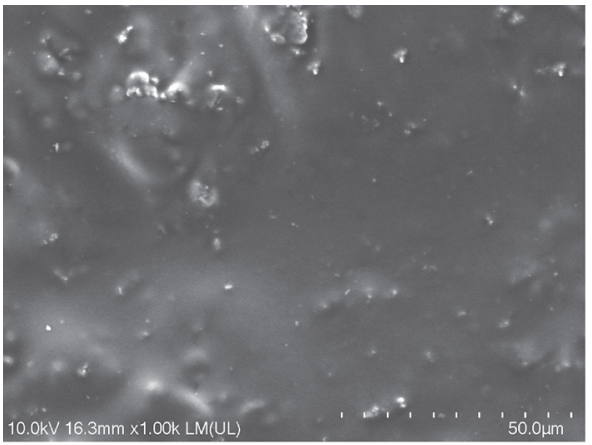

(f)

Figure 3: SEM images: (a) no curing agent was sprayed; (b) spray curing agent $(\mathrm{P} / \mathrm{C}=0.6)$; (c) spray curing agent $(\mathrm{P} / \mathrm{C}=0.8)$; $(\mathrm{d})$ spray curing agent $(\mathrm{P} / \mathrm{C}=1.0) ;(\mathrm{e})$ spray curing agent $(\mathrm{P} / \mathrm{C}=1.2)$; (f) spray curing agent $(\mathrm{P} / \mathrm{C}=1.4)$.

\section{Simulated Slope and Practical Engineering Application}

In this work, a new ecological protection technology for coal gangue slopes is proposed, which involves first spraying with a pure acrylic emulsion curing agent and subsequently spraying into the guest soil. Polymer curing agents are mainly used for the surface protection and reinforcement of coal gangue, and the soil spraying technique is a green technology that benefits ecological protection. The combination of these two technologies results in a new ecological protection-enhancing technology for coal gangue slopes. To analyse the feasibility of the new ecological protection technology, this work studies the effect of the application of the new ecological protection technology on coal gangue slopes through simulated slope tests and practical engineering applications.

\subsection{Simulated Slope Test}

4.1.1. Test Method. The slope simulation test was performed using an outdoor model box. To accurately simulate the gangue slope, a 10-15-cm-thick layer of field sampled coal gangue was placed on the surface of each model box. Two slope model boxes with heights and widths of $1.2 \mathrm{~m}$ were designed and are referred to as model boxes A and B, respectively. Then, each model box was divided into three zones with different heights. In model box A, the surface of the laid coal gangue was directly sprayed with guest soil; in model box B, the surface of the laid gangue was first sprayed with pure acrylic emulsion curing agent with a $\mathrm{P} / \mathrm{C}$ of 1.2 and subsequently sprayed with guest soil after solidification. Other construction methods and conditions are consistent. The proportion of plant seeds sprayed in foreign soil was 50 wt\% herb seeds (30 wt\% Cynodon dactylon (L.) Pers and 20 
wt\% Festuca elata Keng ex E. Alexeev) and 50 wt\% shrub seeds (15 wt\% Sophora xanthoantha C. Y. Ma, 15 wt\% Amorpha fruticosa $L$, and $20 \mathrm{wt} \%$ Magnolia multiflora M. C. Wang et C. L. Min).

All simulated slopes were placed in the open area, and the management measures of seedlings were identical. Observations were made once every two weeks for six months, including the germination rate, coverage rate, height, soil erosion rate, and soil $\mathrm{pH}$ value. A collection tank is placed at the bottom of each simulated slope to collect the soil lost on the slope. The soil in the collection tank was collected and dried every two weeks, and the mass ratio between the collected soil mass and the initial substrate was calculated to evaluate the soil erosion. Model box A after laid coal gangue is shown in Figure 4(a), and model box B after spraying the pure acrylic emulsion curing agent is shown in Figure 4(b).

4.1.2. Results and Analysis. Figure 5 shows the plant growth on the simulated slope. The test results of the simulated slope are shown in Table 6.

As shown in Table 6, the plant germination rate of model box B was much higher than that of A, and the soil of model box A was acidic. The soil of model box B is neutral, which indicates that spraying pure acrylic emulsion curing agent on gangue slopes reduces the influence of weakly acidic coal gangue and heavy metal substances on the plant growth and improves the environment for plant growth. Model box B had a much higher vegetation coverage rate and a much lower soil erosion rate than model box A. With increasing time, the difference increased. These results show that spraying pure acrylic emulsion curing agent can improve the water retention ability of soil, increase the antierosion ability of foreign soil, and improve the growth environment of plants. In model box B, plant germination is high, vegetation coverage is high, and the soil and water loss is low. Three months after construction, vegetation basically covered the slope, and soil erosion was further reduced in the later stage, which benefited the slope protection.

As shown in Figure 5, due to the spraying of pure acrylic emulsion curing agent, the slope of model box B is complete, the vegetation development is much better than that of $\mathrm{A}$, and an elastic consolidation layer with certain strength and toughness is formed on the surface of the slope. Three months after construction, the plants in model box B were mainly herbaceous plants, and the shrubs were mainly in the form of seedlings. Herbaceous and shrubbery grow well six months after construction. Due to the influences of weak acidity and heavy metals in coal gangue, the vegetation of model box A was not well developed. Three months after construction, the growth height of herbaceous plants and germination rate of shrubs were low, and the overall vegetation coverage was low. Six months after construction, most of the herbaceous plants withered, and only a few shrubs grew normally. At the top of the slope of model box A, few plants grew, and the slope scour was serious. With the increase in slope, the scour became increasingly severe and even exposed the laid coal gangue. Thus, the plant seeds sprayed at the slope top of model box A were washed away by rain, the coal gangue disintegrated under the infiltration of rain, and the surface guest soil slid with the disintegrating coal gangue, which resulted in a low plant germination rate and poor slope protection effect. As shown in Figure 6, the roots of slope protection plants do not have difficulty growing into the slope because there is a polymer curing agent layer, and their roots can pass through the sprayed pure acrylic emulsion curing agent layer to achieve ecological slope protection.

The simulated slope test shows that the newly proposed ecological protection method of coal gangue slopes in this paper is feasible. On one hand, the reticulated film of pure acrylic emulsion curing agent can greatly reduce the influence of weathering and leaching on coal gangue and prevent heavy metal elements in coal gangue from entering the surrounding soil. On the other hand, the pure acrylic emulsion curing agent can reduce the loss of water in the slope soil by preventing water from penetrating the rock formation, which improves the growth environment of plants and makes the plants luxuriantly grow, so the roots are developed and play a role of reinforcement for the soil.

4.2. Practical Engineering Application. Taking the coal gangue slope at K68+720 of the Longlang Expressway in Loudi City, Hunan Province, as the application object of the new protection scheme and taking the K72 + 630 coal gangue slope with the ordinary ecological slope protection method as the control, we studied the feasibility of the new protection scheme by evaluating the ecological protection status for both slopes after construction.

4.2.1. Project Overview. The Longlang Expressway starts from Longtang Town, Lianyuan City, Hunan Province, and ends at Langtang Town, Xinhua County, Hunan Province. The route strike zone is located in Xinhua County, Loudi City, Hunan Province, and the mountain trend is basically consistent with the geological structure line, that is, northeast trend. The corridor belt is composed of eroded middle and low mountains and hills. The terrain is generally high in the middle and low on the east and west sides. The tectonic denudation and dissolution in the area are strong with high mountains and steep slopes, developed gullies, mostly northeast trending gullies, and "V"-shaped gullies and valley sections. The surface water system is relatively developed, the bedrock is mostly exposed, and the vegetation is less developed. Some areas are abandoned mining areas. Many coal gangue slopes are formed by subgrade excavation with poor construction conditions and difficult ecological restoration.

4.2.2. Construction Method. First, the slope surface was levelled, depressions and cracks were filled, dangerous stones and pumice on the slope surface were removed, and the slope surface was wetted with water. Then, the wet jet machine was segmented, the pure acrylic emulsion curing agent was sprayed from top to bottom, and the spraying 


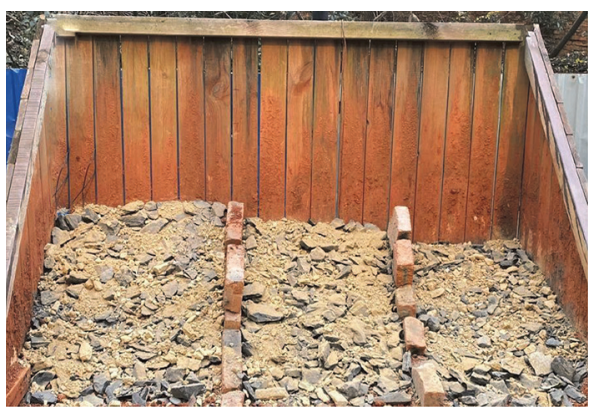

(a)

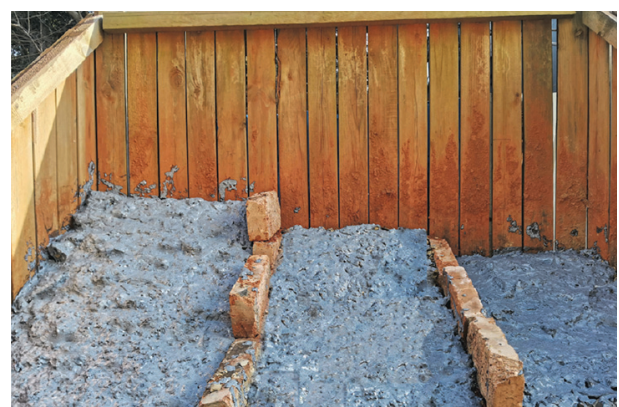

(b)

Figure 4: (a) Model box A after the laid coal gangue; (b) model box B after spraying the pure acrylic emulsion curing agent.

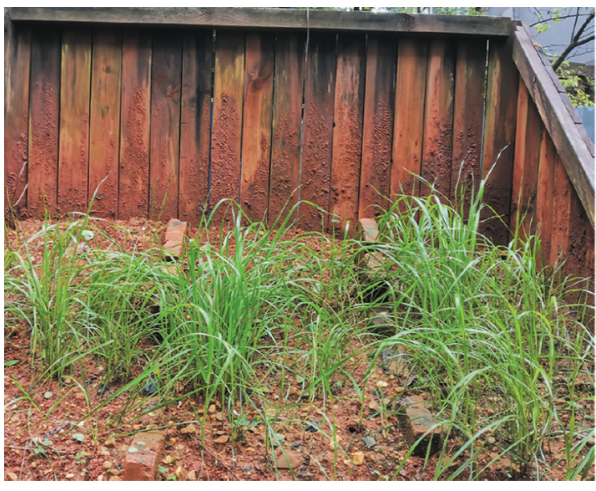

(a)

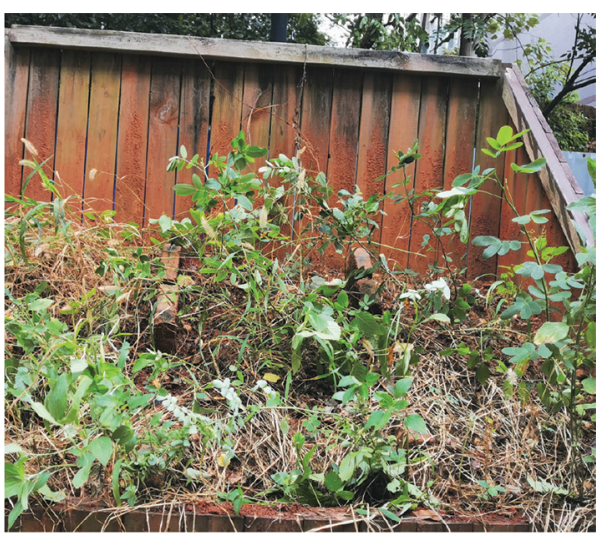

(c)

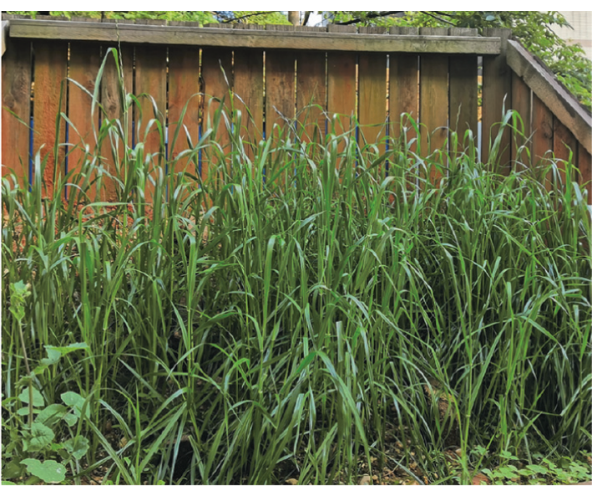

(b)

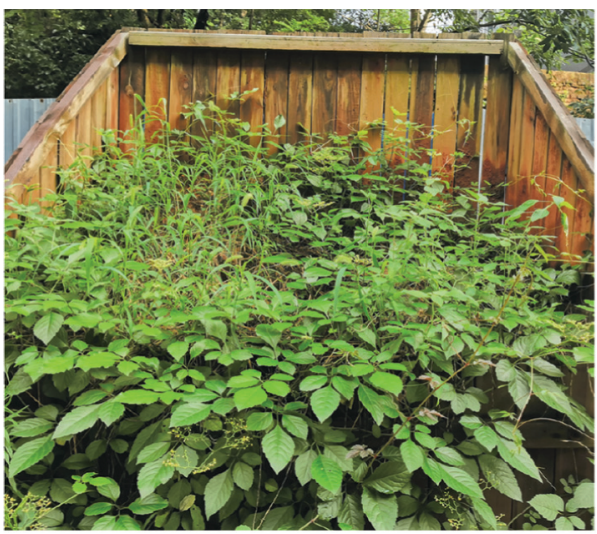

(d)

Figure 5: Plant growth on the simulated slope: (a) model box A after three months of construction; (b) model box B after three months of construction; (c) model box A after six months of construction; (d) model box B after six months of construction.

TABLE 6: Test results of the simulated slope.

\begin{tabular}{lccccccc}
\hline & Ratio of germination (\%) & \multicolumn{3}{c}{ Vegetation coverage (\%) } & \multicolumn{3}{c}{ Cumulative soil erosion (\%) } \\
Time (d) & 30 & 30 & 90 & 180 & 30 & 90 & 180 \\
\hline Model box A & 52.3 & 21.2 & 31.5 & 36.7 & 13.6 & 23.1 & 33.4 \\
Model box B & 86.4 & 36.6 & 87.4 & 92.4 & 4.7 & 6.7 & 8.2 \\
\hline
\end{tabular}

thickness was 6-8 mm. After the curing agent was completely solidified, the guest soil was sprayed. The method of external-soil spray seeding is as follows: first, the guest soil was sprayed without seeds, and the spraying thickness was approximately $7 / 10$ of the actual spraying and sowing thickness of guest soil. Second, after the subbase was stable, the guest soil containing seeds was sprayed, and the spraying thickness was approximately $1 / 10$ of the actual spraying 


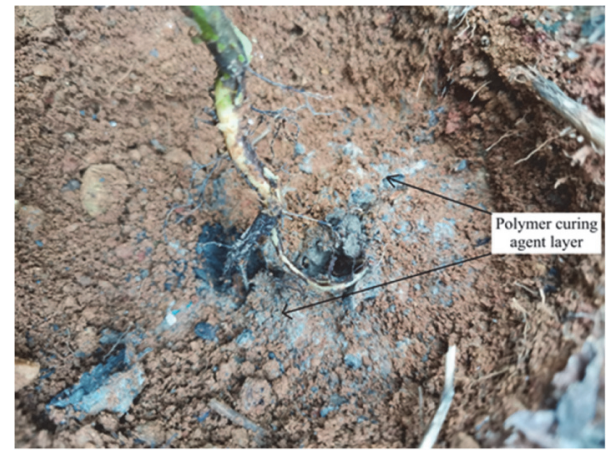

FIGURE 6: Plant roots passing through the curing agent layer.

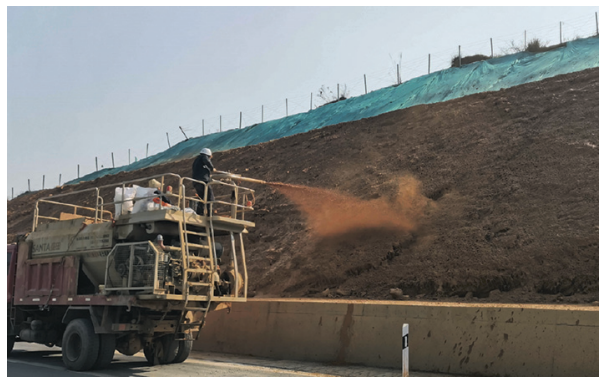

FIGURE 7: External-soil spray seeding.

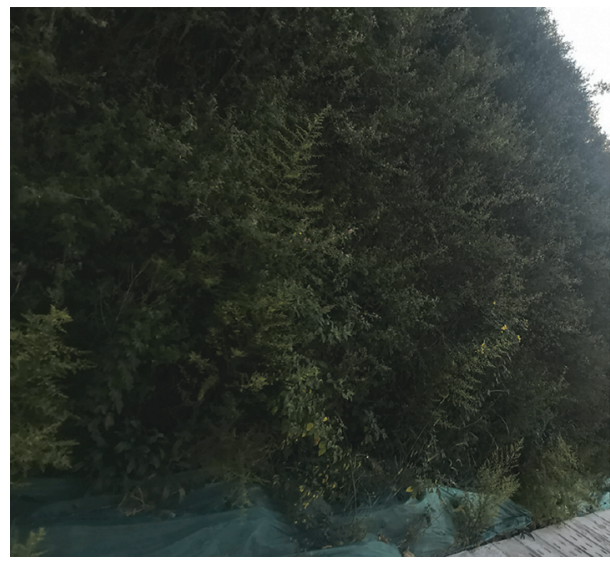

(a)

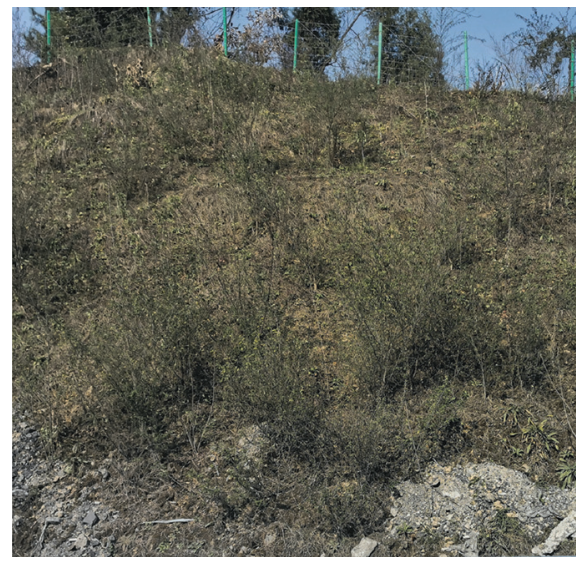

(b)

Figure 8: Test coal gangue slope one year after construction: (a) with added polymer curing agent; (b) without polymer curing agent.

thickness of the substrate. Finally, guest soil without seeds was sprayed, the spraying thickness was approximately 1/5 of the actual spraying thickness, and the total spraying thickness was $18-22 \mathrm{~cm}$. External-soil spray seeding is shown in Figure 7.

4.2.3. Results and Analysis. The test coal gangue slope one year after construction is shown in Figure 8. Figure 8 shows that the coal gangue slope constructed by the traditional ecological slope protection method has poor plant development, low vegetation coverage, and obvious rainwater scouring traces on the slope. The coal gangue slope constructed by the new protection method with a polymer curing agent shows good results. Its slope greening is essentially covered, the vegetation is well developed, the environmental quality is clearly optimized, and the effect of slope protection and ecological restoration is preliminarily manifested. Thus, the new ecological protection technology of coal gangue slopes combined with external-soil spray seeding and polymer curing agents can achieve slope protection and ecological restoration and can be popularized and applied in similar projects. 


\section{Conclusions}

In this paper, pure acrylic emulsion and ordinary Portland cement were used as the main raw materials to prepare an organic polymer curing agent, and the best mixing ratio was experimentally determined. Then, its protection mechanism was analysed. Finally, a new ecological protection technology for coal gangue slopes with pure acrylic emulsion curing agents was proposed, and its protection effect was analysed through slope simulation and practical engineering applications. The main conclusions are as follows.

(1) The pure acrylic emulsion curing agent with a $\mathrm{P} / \mathrm{C}$ of 1.2 satisfies the requirements of workability, water resistance, durability, and bond strength and is most suitable to protect coal gangue slopes.

(2) Polymer particles of pure acrylic emulsion and hydration products of cement were interwoven to form a network film with good waterproof ability; the film covered the coal gangue surface to prevent the weathering and disintegration of coal gangue and improve the stability of coal gangue slopes.

(3) The net film layer of the pure acrylic emulsion curing agent greatly reduces the influence of weathering and leaching on the coal gangue, prevents the heavy metal elements in the coal gangue from entering the surrounding soil, increases the water storage capacity of slope soil, and improves the growth environment of plants. Moreover, plant roots can pass through the pure acrylic emulsion curing agent layer, and the presence of a curing agent does not affect the growth of plant roots.

(4) Simulated slope tests and practical engineering applications prove that stabilizing the surface of the slope by first using a pure acrylic emulsion curing agent and subsequently spraying guest soil is a new method to ecologically protect coal gangue slope. This new method can achieve slope protection and ecological restoration, and it has high popularization and application value.

\section{Data Availability}

The data used to support the findings of this study are included within the article.

\section{Conflicts of Interest}

The authors declare that they have no conflicts of interest.

\section{Acknowledgments}

This research was supported by the Introduction of Key Technologies for Landscape Restoration of Deep Cut Slopes (State Forestry Administration, China; no. 2015-4-38) and Research on Key Technology of Ecological Landscape Restoration of Highway Slope Road in Ecological Fragile Area (Hunan Provincial Department of Communications, China; no. 201803). The authors thank all who contributed to the imaging technique and experimental part of this study.

\section{References}

[1] J. Yan, X. Chen, Y. Cai, and H. Huang, "Physicochemical property change regularities of coal gangue with different weathering ages in Huainan minging area," Transactions of the Chinese Society of Agricultural Engineering, vol. 33, no. 3, pp. 168-174, 2017.

[2] W. Fan, H. Li, Z. Bai, and J. Qiao, "Effect of gangue spontaneous combustion on reclaimed soil quality of large-scaled opencast mine in loess area," Transactions of the Chinese Society of Agricultural Engineering, vol. 26, no. 2, pp. 319-324, 2010.

[3] X. Querol, M. Izquierdo, E. Monfort et al., "Environmental characterization of burnt coal gangue banks at Yangquan, Shanxi Province, China," International Journal of Coal Geology, vol. 75, no. 2, pp. 93-104, 2008.

[4] S. Chen, Z. Hu, and S. Chen, "Construction of isolation layers for preventing spontaneous combustion of coal gangue dump and its effects," Transactions of the Chinese Society of Agricultural Engineering, vol. 30, no. 2, pp. 235-243, 2014.

[5] H. He, F. F. Hong, X. X. Tao, and G. Huang, "A study on soil basic characteristics, main microbial flora and typical metal fraction surrounding coal gangue dump in Xiangtan Hunan Province, south of China," Environmental Earth Sciences, vol. 75, no. 6, Article ID 488, 2016.

[6] A. Khalil, L. Hanich, A. Bannari, L. Zouhri, O. Pourret, and R. Hakkou, "Assessment of soil contamination around an abandoned mine in a semi-arid environment using geochemistry and geostatistics: pre-work of geochemical process modeling with numerical models," Journal of Geochemical Exploration, vol. 125, pp. 117-129, 2013.

[7] N. Tripathi, R. S. Singh, and C. D. Hills, "Soil carbon development in rejuvenated Indian coal mine spoil," Ecological Engineering, vol. 90, pp. 482-490, 2016.

[8] M. Gomo and D. Vermeulen, "Hydrogeochemical characteristics of a flooded underground coal mine groundwater system," Journal of African Earth Sciences, vol. 92, pp. 68-75, 2014.

[9] Y. Yao, J. Ni, and J. Li, "Stress-dependent water retention of granite residual soil and its implications for ground settlement," Computers and Geotechnics, vol. 129, Article ID 103835, 2021.

[10] M. J. Chadwick, "Methods of assessment of acid colliery spoil as a medium for plant growth," Ecology and Reclamation of Devastated Land International Symp on Ecol and Reveg of Drastically Disturbed Areas, vol. 1, pp. 81-91, 1973.

[11] J. C. Fan, C. L. Huang, C. H. Yang, and K. Liao, "Effect evaluation of shotcrete vegetation mulching technique applied to steep concrete-face slopes on a highway of Taiwan," Paddy and Water Environment, vol. 11, no. 1, pp. 145-159, 2013.

[12] D. H. Lee, Y. E. Yang, and H. M. Lin, "Assessing slope protection methods for weak rock slopes in Southwestern Taiwan," Engineering Geology, vol. 91, no. 2-4, pp. 100-116, 2007.

[13] J. Zhang, A. Zhang, C. Huang, and H. Yu, "Characterising the resilient behaviour of pavement subgrade with construction and demolition waste under Freeze-Thaw cycles," Journal of Cleaner Production, vol. 300, Article ID 126702, 2021.

[14] J. Y. Wu, K. Huang, and M. Sungkar, "Remediation of slope failure by compacted soil-cement fill," Journal of Performance of Constructed Facilities, vol. 31, no. 4, Article ID 04017022, 2017. 
[15] E. Blanco-Fernandez, D. Castro-Fresno, J. J. del Coz Diaz, A. Navarro-Manso, and M. Alonso-Martinez, "Flexible membranes anchored to the ground for slope stabilisation: numerical modelling of soil slopes using SPH," Computers and Geotechnics, vol. 78, pp. 1-10, 2016.

[16] L.-j. Su, B.-l. Hu, Q.-j. Xie, F.-w. Yu, and C.-1. Zhang, "Experimental and theoretical study of mechanical properties of root-soil interface for slope protection," Journal of Mountain Science, vol. 17, no. 11, pp. 2784-2795, 2020.

[17] A. Medl, R. Stangl, and F. Florineth, "Vertical greening systems - a review on recent technologies and research advancement," Building and Environment, vol. 125, pp. 227-239, 2017.

[18] Q. Ma, C. Huang, H. Xiao, and Q. Chen, "Thermal properties of carbon fiber-reinforced lightweight substrate for ecological slope protection," Energies, vol. 12, no. 15, Article ID 2927, 2019.

[19] P. Jiang, J. Li, S. Zuo, and X. Cui, "Ecological retaining wall for high-steep slopes: a case study in the ji-lai expressway, eastern China," Advances in Civil Engineering, vol. 2020, Article ID 5106397, 2020.

[20] H. Fu, H. Zha, L. Zeng, C. Chen, C. Jia, and H. Bian, "Research progress on ecological protection technology of highway slope: status and challenges," Transportation Safety and Environment, vol. 2, no. 1, pp. 3-17, 2020.

[21] M. E. W. Sydnor and E. F. Redente, "Reclamation of highelevation, acidic mine waste with organic amendments and topsoil," Journal of Environmental Quality, vol. 31, no. 5, pp. 1528-1537, 2002.

[22] B. Liu, Z. Tang, S. Dong, L. Wang, and D. Liu, "Vegetation recovery and groundwater pollution control of coal gangue field in a semi-arid area for a field application," International Biodeterioration \& Biodegradation, vol. 128, pp. 134-140, 2018.

[23] T. Du, D. Wang, Y. Bai, and Z. Zhang, "Optimizing the formulation of coal gangue planting substrate using wastes: the sustainability of coal mine ecological restoration," Ecological Engineering, vol. 143, Article ID 105669, 2020.

[24] P. V. Barry, R. F. Turco, D. E. Stott, and J. M. Bradford, "Organic polymers' effect on soil shear strength and detachment by single raindrops," Soil Science Society of America Journal, vol. 55, no. 3, pp. 799-804, 1991.

[25] W. Huang, Z. Liu, C. Zhou, and X. Yang, "Enhancement of soil ecological self-repair using a polymer composite material," Catena, vol. 188, Article ID 104443, 2020.

[26] M. A. Mohsin and N. F. Attia, "Inverse emulsion polymerization for the synthesis of high molecular weight polyacrylamide and its application as sand stabilizer," International Journal of Polymer Science, vol. 2015, Article ID 436583, 2015.

[27] B. Zhang, W. Jiang, Q. Xu, D. Yuan, J. Shan, and R. Lu, "Experimental feasibility study of ethylene-vinyl acetate copolymer (EVA) as cement stabilized soil curing agent," Road Materials and Pavement Design, vol. 2020, pp. 1-22, 2020.

[28] J. Li, J. Zheng, Y. Yao, J. Zhang, and J. Peng, "Numerical method of flexible pavement considering moisture and stress sensitivity of subgrade soils," Advances in Civil Engineering, vol. 2019, Article ID 7091210, 2019.

[29] Q. Y. Mu, C. Zhou, and C. W. W. Ng, "Compression and wetting induced volumetric behavior of loess: macro-and micro-investigations," Transportation Geotechnics, vol. 23, Article ID 100345, 2020.

[30] J. Yuan, C. Ye, L. Luo et al., "Sand fixation property and erosion control through new cellulose-based curing agent on sandy slopes under rainfall," Bulletin of Engineering Geology and the Environment, vol. 79, no. 8, pp. 4051-4061, 2020.

[31] J. Liu, B. Shi, H. T. Jiang, and H. Huang, "Experimental study on the water-stability property of clay aggregates stabilized by STW polymer soil stabilizer," Hydrogeology \& Engineering Geology, vol. 36, no. 2, pp. 77-80, 2009.

[32] J. Liu, B. Shi, H. Jiang, and H. Huang, "Research on the stabilization treatment of clay slope topsoil by organic polymer soil stabilizer," Engineering Geology, vol. 117, no. 1-2, pp. 114-120, 2011.

[33] J. Liu, B. Shi, and K. Gu, "Laboratory study on soil modified by polyurethane sand-fixing agents," Journal of Disaster Prevention and Mitigation Engineering, vol. 33, no. 1, pp. 29-34, 2013.

[34] Q.-w. Yang, X.-j. Pei, and R.-q. Huang, "Impact of polymer mixtures on the stabilization and erosion control of silty sand slope," Journal of Mountain Science, vol. 16, no. 2, pp. 470-485, 2019.

[35] D. Yao, G. Qian, J. Liu, and J. Yao, “Application of polymer curing agent in ecological protection engineering of weak rock slopes," Applied Sciences, vol. 9, no. 8, Article ID 1585, 2019.

[36] X. Qin, A. Ni, N. Zhang, and Z. Chen, "Erosion control and growth promotion of w-oh material on red clay highway slopes: a case study in South China," Sustainability, vol. 13, no. 3, Article ID 1144, 2021.

[37] Chinese Standard, Test Methods for Water Requirement of normal Consistency, Setting Time, and Soundness of the portland Cement, China Standards Press, GBT1346, Beijing, China, 2011.

[38] Chinese Standard, Verification Regulation of Rotational Viscometers, China Measurement Press, JJG 1002, Beijing, China, 2005.

[39] Chinese Standard, Test Methods of Rock for Highway Engineering, China Communications Press, JTG E41, Beijing, China, 2005.

[40] Chinese Standard, Polymer Modified Cement Mortar for waterproof, China Standards Press, JC/T 984-2011, Beijing, China, 2011.

[41] Chinese Standard, Standard for Test Method of Basic Properties of Construction Mortar, China Standards Press, JGJ T70, Beijing, China, 2009. 